\title{
Students' Mathematical Communication Skills (MCS) in Solving Mathematics Problems: A Case in Indonesian Context
}

Nabrisi Rohid

A Graduate student of Educational Technology Program of Universitas PGRI Adibuana, Surabaya, Indonesia, rohidnabrisi88@gmail.com

Suryaman

The Lecturer of Graduate Program of Universitas PGRI Adibuana, Surabaya, Indonesia, maman_suryaman58@yahoo.com

Retno Danu Rusmawati

The Lecturer of Graduate Program of Universitas PGRI Adibuana, Surabaya, Indonesia, retno.danu@unipasby.ac.id

Mathematical Communication Skills (MCS) refer to the students' ability to (1) arrange and link their mathematical thinking through communication; (2) communicate their logical and clear mathematical thinking to their friends, teachers, and others; (3) analyze and assess mathematical thinking and strategies used by others; and (4) use mathematical language to express mathematical ideas correctly. Referring to the importance of MCS in mathematics problemsolving, this study was intended to analyze students' mathematical communication skills in solving a mathematics problem. This study employed a case study design with the participants of the study were 3 students of the eighth-grade of Junior High School in Indonesia. The data of this study was dug up through observation, documentation, and interview. The findings reveal that only 1 out of 3 students' is able to express mathematical ideas; understand, interpret and assess or respond to mathematical ideas; and use terms, notations, and symbols to present mathematical ideas. This study implies that the students' mathematical communication skills are still needed to be developed. This study should be taken into account by the Mathematics teachers to not only teach mathematics but also stimulate the students' mathematical communication skills through creative and innovative learning activities.

Keywords: Mathematical Communication Skill (MCS), mathematics, problem-solving, group discussion, case study

\section{INTRODUCTION}

Mathematics is generally identical to the calculation of figures and formulas, giving rise to the notion that communication skill cannot be built on learning mathematics. Communication skills are very important in the learning of mathematics. Mathematical communication is one of the standard processes in Mathematics learning proposed by the National Council of Teachers of Mathematics (NCTM, 2000). Mathematical Communication Skills (MCS) refer to the students' ability to (1) arrange and link their mathematical thinking through communication; (2) communicate their logical and clear mathematical thinking to their friends, teachers, and others; (3) analyze and assess mathematical thinking and strategies used by others; and (4) use mathematical language to express

Citation: Rohid, N., Suryaman, \& Rusmawati, R. D. (2019). Students' Mathematical Communication Skills (MCS) in Solving Mathematics Problems: A Case in Indonesian Context. Anatolian Journal of Education, 4(2), 19-30. https://doi.org/10.29333/aje.2019.423a 
mathematical ideas correctly, (NCTM, 2000). According to Pourdavood and Wachira (2015), one of key components which could affect the success in mathematics is the need to attend to precision which explicitly calls for students to attend to precision both calculation and language. Language or communication in Mathematics is an important part of Mathematics education as a means to exchange ideas and tools to clarify understanding. In addition, learning mathematics in the classroom should help students to communicate their ideas. The ability of mathematical communication should be developed as described by Manouchehri (2007); Manouchehri and St. John (2006), that communication in learning mathematics contributes to deeper analyses of mathematics on the part of teachers as well as students.

In classroom interaction, all the classroom events are included, both verbal interaction and non-verbal interaction (Rohmah, 2017). Another term for interaction is communication or discourse. The use of discourse is very important that it fits into communication standard which calls for Instructional programs to enable all students to communicate their mathematical thinking coherently and clearly to peers, teachers, and others; to analyze and evaluate the mathematical thinking and strategies of others and to use the language of mathematics to express mathematical ideas precisely. According to Schwols and Dempsey (2012b), there are several components to high quality mathematics discourse. One of these is facilitation of conversation. The level and effectiveness of classroom discourse depends heavily on the facilitation skills of the teacher. Another in dispensable component of mathematical discourse is formal mathematical language. The quality of classroom discourse depends on the ability of students to process language in order to build on the ideas of others. The ability to process language promotes mathematical thinking (Kabasakalian, 2007). Students need to know the meaning of mathematics vocabulary words, whether written or spoken, in order to better understand and communicate mathematical ideas (Gay, 2008).

Dealing with students' mathematical communication skills in Indonesia, Rustam and Ramlan (2017) stated students' MCS, especially those who are in the level of Junior High Schools, are still very lacking. Referring to that statement, mathematical communication skills for students should be a major concern for teachers. According to Mullis, Martin, Foy, and Arora (2012), Trends in International Mathematics Science Study (TIMSS) 2011 international results in Mathematics placed Indonesia at the rank of 36 out of 48 countries. Meanwhile, the Organization for Economic Co-operation and Development (OECD, 2010) reveals that the results of Program for International Student Assessment (PISA) in the year of 2009 placed Indonesia at the ranked 52 out of 65 countries. This fact is very alarming for our education in the homeland. It shows that students' mathematics achievement, especially in junior high school is still very low.

Communication in mathematics has been given a great deal of attention over the past 20 years. According to Ezrailson, Kamon, Loving, and McIntyre (2006: 278), teaching is an activity that presumes some form of communication. With this in mind, those researchers went on to state that students will only retain $20 \%$ of what they hear, $30 \%$ of what they see and $50 \%$ of what they see and hear (Ezrailson, et. al., 2006: 278). However, when teachers focus on interaction and communication in the classroom, students will retain $90 \%$ of what they say and do as they engage in discussions (Ezrailson et al., 2006: 278). It is clear in this research that communication is an important factor in enhancing the quality of students' learning and understanding in the mathematics subject area. To further demonstrate the significance of communication in mathematics, the National Council of Teachers of Mathematics (NCTM) (2000) had included a communication standard as part of the Principles and Standards for School Mathematics. In this way, communication has been placed at the forefront of the mathematics curriculum so that all teachers recognize the importance of this skill and work towards providing students with ample opportunities to engage in mathematical talk.

According to Ontario Ministry of Education in Ontario Mathematics Curriculum (2005: 17), communication is the process of expressing mathematical ideas and understanding orally, visually, and 
in writing, using numbers, symbols, pictures, graphs, diagrams, and words. In this respect, communication can take the form of both verbal and written responses to the materials and activities provided to students which will allow them greater opportunities to gain conceptual understandings of mathematics. Also, in her research on the effects of communication on the participation of seventh graders in their mathematics classrooms, Jansen (2006: 410) found that a classroom discussion with a focus on correct answers may be more threatening than one that emphasizes understandings. Through this research, it is clear that communication is critical to the success of students in today's classrooms as they will have more opportunities to develop conceptual understandings of concepts through physically and verbally engaging in their learning.

Facilitating effective peer-to-peer and student-to-teacher communication is an important aspect of the teaching of mathematics. This not only allows students to consolidate their knowledge and understandings of concepts through discussions but also gives the students multiple opportunities to build confidence in a supportive environment that is open to discussing new and creative thoughts and conducive to supporting and empowering students with different abilities and strengths.

Small (2013: 119) had also stated that communication in mathematics, whether silent self-talk or communication with peers or a teacher, is essential to students as they learn; it is also a critical assessment tool for teachers. In addition, Bishop (2012: 69) stated that monitoring student talk enables one to identify who participates and how, who does not participate and why, and what kinds of mathematics identities students are enacting. Both Small (2013) and Bishop (2012) confirmed that research on the importance of communication plays in facilitating students' understandings and providing teachers with multiple opportunities to assess students' abilities in order to further guide mathematics instructions so that it is in line with the students' current understandings of the concepts being taught.

Communication, both verbal and written, allows teachers to immediately hear and see the students' current abilities and understandings so that immediate feedback and, if necessary, immediate intervention can be provided so as to guide the students in the correct direction. In this respect, Williams and Casa (2012: 314) had stated that their writing serves as a culminating activity that allows me to better assess the depth of each students' understanding following class activities and discussions.

Dealing with the background above, the aim of this study was to analyze students' mathematical communication skills in solving a mathematics problem. In this study, the way the students solve mathematical problems, started from the discussion, identifying facts and data, converting narrative questions into mathematical symbols and notations are investigated.

\section{METHOD}

\section{Design}

To meet the objective of this study, a case study design was employed. Yin (2003) elaborates that "case study is used in many situations to contribute to our knowledge of the individual, group, organizational, social, political, and related phenomena. Based on the characteristics listed above, the case study design was used in this study in order to provide rich and detailed information dealing with the students' mathematical communication skills in solving a mathematics problem.

\section{Participants}

The participants of this study were 3 of the eighth-grade students of Junior High School in SMPN 1 Senori Tuban, East Java, Indonesia. The participants were selected by using purposive sampling technique, in this case, is criterion sampling, in order to purposefully select participants to maximize information. According to Patton (2002), criterion sampling involves cases that meet some predetermined criterion of importance. The predetermined criteria used to choose the participants were (1) a willingness to get involved in the study, (2) an experience in a group discussion activity (since 
they will be grouped to conduct a discussion and observed their verbal mathematical communication among group members and teacher), and (3) a good mathematics achievement record. Based on those considerations, the three participants were selected for this study. According to Dworkin (2012), the sample size used in qualitative research methods is often smaller than that used in quantitative research methods. This is because qualitative research methods are often concerned with garnering an in-depth understanding of a phenomenon or are focused on meaning which are often centered on the how and why of a particular issue, process, situation, subculture, scene or set of social interactions.

\section{Data Collection Technique}

\section{Observation}

Direct observation was done to get clear data on students' MCS. When the students conducted a group discussion to solve the mathematical problems given, the researchers observed that activity and focus on how the students express mathematical ideas, understand, interpret and assess or respond to mathematical ideas. The students' verbal communication among the group members and with the teacher was fully analyzed.

\section{Documentation}

The documents of the results of the mathematics test from the participants were also analyzed. This analysis was focused on the use of terms, notations, and symbols to present mathematical ideas. In other words, this documents analysis was to know the students' written mathematical communication.

\section{Interview}

An in-depth interview was also done in this study to get more comprehensive data on students' MCS. Through this interview, some findings from observation and documents analysis were directly clarified and confronted with the participants. Data from the interviews were recorded and collected. The responses from the interview were transcribed for analysis by using the coding processes. Coding process was used as it is more practical for the researcher to classify the data into specific categories and terms, related to the study. The coding is then manually typed into Microsoft Words for the transcribing of data.

\section{Data Analysis}

After the data was gotten, then, it was analyzed by examining the "bottom-up" approach to analysis. The researcher first collected data and then prepared it for data analysis. This analysis initially consists of developing a general sense of the data, and then coding description and themes about the central phenomenon (Creswell, 2012). In this study, coding schemes were used to gain a more detailed perspective about what was occurring based on the purpose of the study. These coding schemes helped to analyze the transcripts of the participants.

\section{Research Context and Procedures}

This study was done in Indonesian Junior High School context, especially in Tuban Regency, East Java Province. The participants of this study were given a narrative question of mathematics problem. Then, they had to discuss it in the group to solve the problem. The time allotment for the discussion is 15 minutes. The question is as follows:

"Budi has 14 dozen books. The number of Zahra and Nadia's books is as many as of Budi and Rani's books. Meanwhile, the number of Zahra's books is $3 / 4$ of Rani's, and the number of Nadia's books is 5 dozen less than the number of Rani's books. How many books does Rani have?"

In a small group consisted of 3 students, the participants had to discuss the question given. The teacher also guided them in case if they did not understand the question well. During the discussion, they were directly observed by the researchers to know how they communicate among others and also with the teacher to solve the mathematical problem given. After they finished the discussion, they wrote down 
their answer on a piece of paper and submitted their works to their teacher. The documents of the students' answer, then, were also analyzed further to know how they used terms, notations, and symbols to present mathematical ideas before they finally got the result or answer of the question. After that, the participants were interviewed deeply dealing with the findings found during observation and documents analysis.

\section{FINDINGS AND DISCUSSION}

\section{Students' Mathematical Communication Skills (MCS) in Solving Mathematics Problem}

After the teacher gave a narrative question to the participants, the teacher instructed them to make a small group for discussion. During the discussion, the teacher also accompanied them in case they have some questions dealing with the problem given. Further, the researcher observed the discussion by focusing on how the students express mathematical ideas, understand, interpret and assess or respond to mathematical ideas. The followings are the results of observation.

The first subject started the discussion by reading the question three times and tried to understand every single word in the question. The second-and-third subject also did the same thing. The first subject continued explaining the question to their partners by making some notes with mathematical symbols. Then, partners responded by nodding their heads and also tried to write something with mathematical symbols. They identified the data and facts from the question, such as the number of Budi's books is 14 dozen which equals 168 books, and so forth. Along the 15 -minutes of discussion, the first subject dominated their partners. He talked mostly than his two partners. His two partners only responded by replying him with some short sentences showing their agreement or disagreement, clarifying the unclear statement, and adding more explanation. The first subject was very fluent in speaking both in case of giving the explanation to their partners and asking for more explanation to the teacher during the discussion. Meanwhile, the second-and-third subject was more passive. Once they spoke up, they seemed to think hard to express what they wanted to say. Even, when they asked for more explanation to the teacher, the teacher did not directly understand what they meant. Consequently, the teacher asked them to re-explained their question in more detail. From this observation, it was revealed that only the first subject has good MCS in term of oral/verbal communication. Meanwhile, the other subjects have an average skill of MCS. This conclusion was based on the indicator of how they expressed mathematical ideas, understood, interpreted and assessed or responded to mathematical ideas.

The second instrument used in this study was documentation. The document, here, refers to the results of students' answers toward the question given. The documents were analyzed to reveal how the students used terms, notations, and symbols to present their mathematical ideas. In other words, this documents analysis was to know the students' written mathematical communication. The followings are the results of documents analysis.

\section{The first subject}

The first subject wrote the mathematical symbols, notations, and terms very well. He converted the narrative question given into mathematical symbols before he tried to solve the problem. As the complete question was: Budi has 14 dozen books. The number of Zahra and Nadia's books is as many as of Budi and Rani's books. Meanwhile, the number of Zahra's books is 3/4 of Rani's, and the number of Nadia's books is 5 dozen less than the number of Rani's books. How many books does Rani have?". The first subject, firstly, identified the data and facts stated in the question and converted those

data into mathematical symbols, such as: Budi=14 dozen $=14 \times 12=168$ books ; 


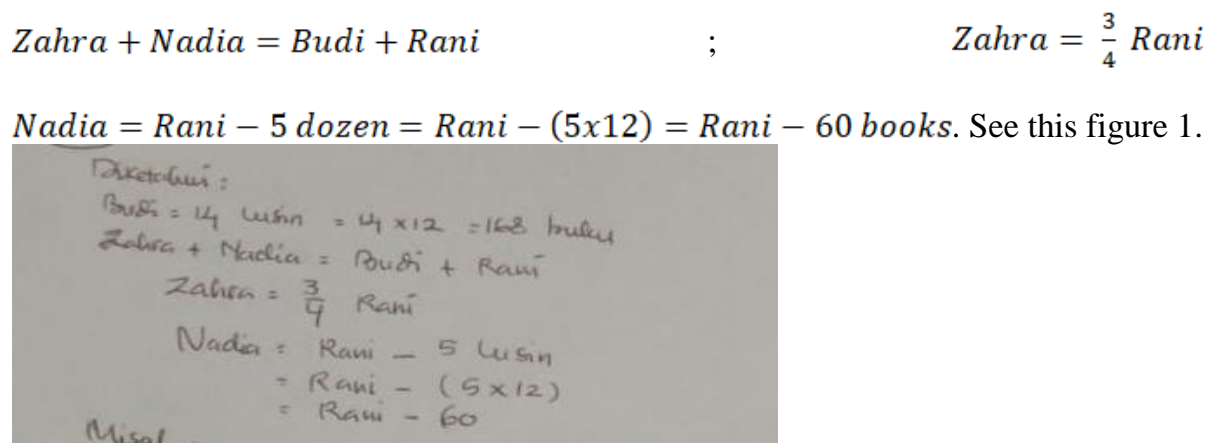

Figure 1

The Results of Facts Identification by the First Subject

Then, from the facts provided in the question, he made other mathematics symbols and notations in order to easily answer the question. Budi was symbolized with 'a', Zahra was symbolized with ' $b$ ', Nadia was symbolized with 'c', and Rani was symbolized with 'd'. See this figure 2.

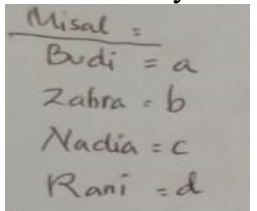

Figure 2

Mathematics Symbols made by the First Subject

After that, he tried to solve the problem by operating those mathematical symbols and notations. The result of his answer was presented in the following figure.

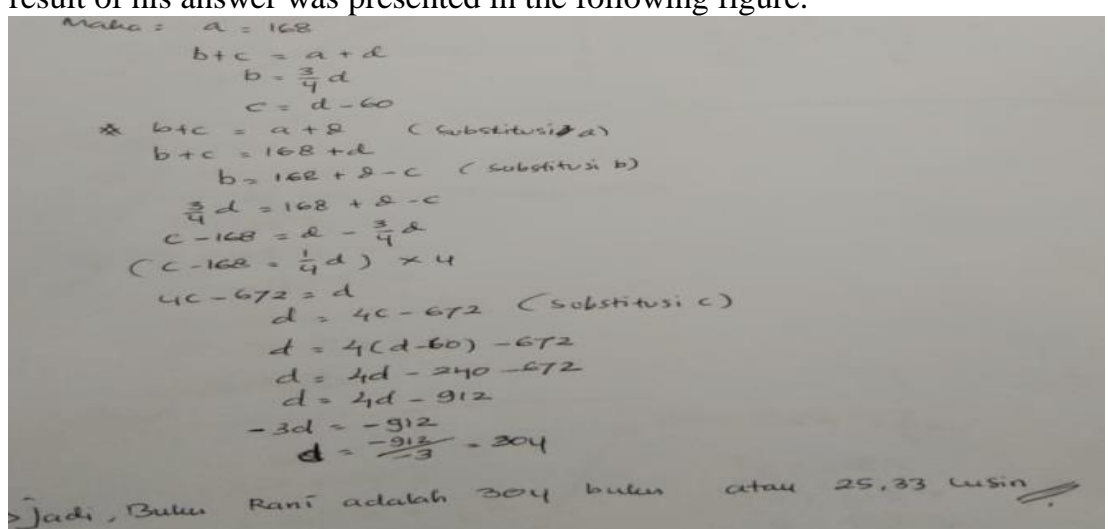

Figure 3

The First Subject's Operation of Mathematical Symbols and Notations to Solve the Problem

From figure 3 above, it is clearly seen that the first subject converted the questions into mathematical symbols and notations and arranged them in very good order. The mathematical symbols and notations he made were easy to understand. Therefore, he could solve the problem correctly. From the first subject's writing, it was also revealed that he wrote the symbols and notations confidently so that he could write the symbols and notations fluently. Therefore, there is almost no correction made in his writing. This shows that the first subject has a good MCS in terms of written language indicated by his good ability to use of terms, notations, and symbols to present mathematical ideas. 


\section{The second subject}

From the second subject's answer sheet, it was revealed that he started his answers by making mathematics symbols and identifying facts and data. The symbols were made from the initial name of the characters stated in the question. Budi was symbolized with 'B', Zahra was symbolized with ' $Z$ ', Nadia was symbolized with ' $N$ ', and Rani was symbolized with 'R'. Although these symbols are still acceptable, however, it is quite strange in Mathematics. See this figure 4.

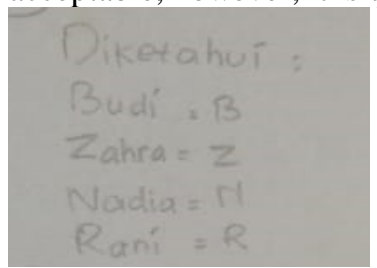

Figure 4

Mathematics Symbols made by the Second Subject

Then, he started to identify the facts. He wrote that $B=14$ dozen $=14 \times 12=168$ books ; $Z+N=B+R ;{ }^{Z}=\frac{3}{4} R{ }_{;} N=R-5$ dozen $; R=\cdots ?$. See this figure 5 .

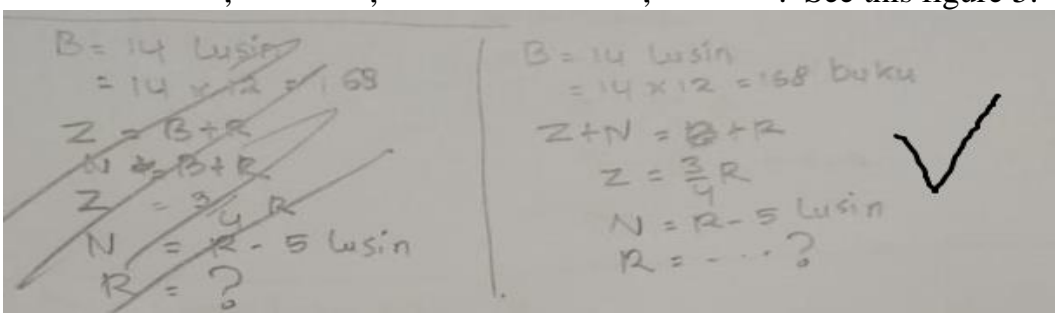

Figure 5

The Results of Facts Identification by the Second Subject

From figure 5 above, it is seen that he first made an incorrect identification of facts. Then, he rewrote it next to the initial identification. After that, he operated those mathematical symbols and notations to solve the problem. The result of his answer was presented in the following figure.

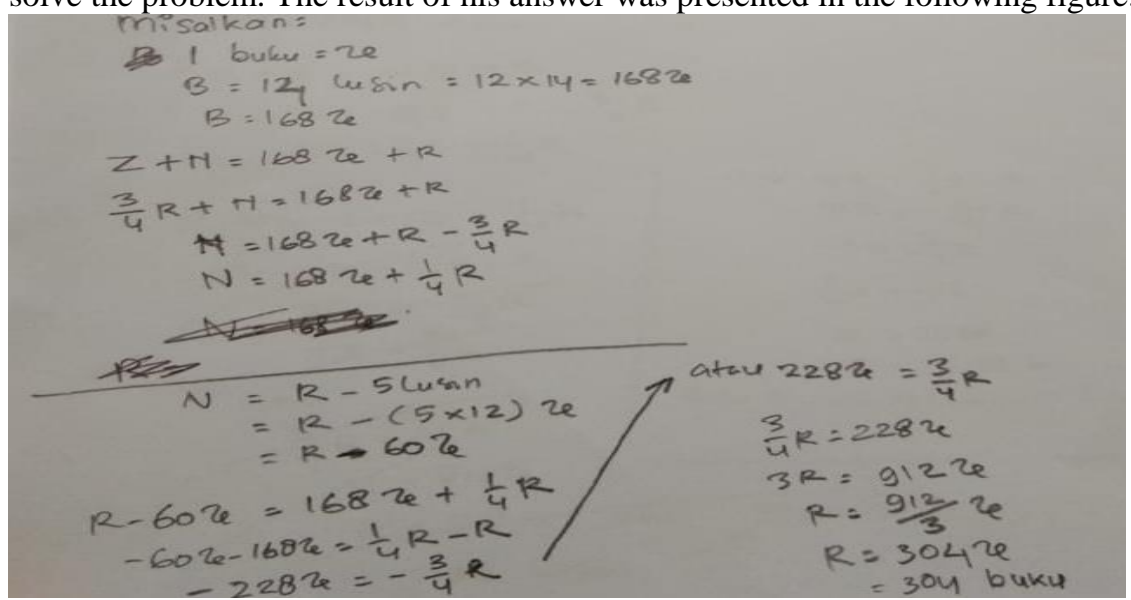

Figure 6

The Second Subject's Operation of Mathematical Symbols and Notations to Solve the Problem

Anatolian Journal of Education, October $2019 \bullet$ Vol.4, No.2 
From the figure 6 above, it is revealed that the second subject also made new symbols and notations,

such as 1 book $=x ; B=14$ dozen $=12 \times 14=168 x$, then, he started to use the symbols in his mathematical operations. However, he also made a mistake in writing the symbols in which he scribbled on the wrong part. At last, he also could solve the problem and answer the question correctly. From this document analysis, it can be inferred that the second subject has the average skill of MCS in terms of written language indicated by his average ability to use of terms, notations, and symbols to present mathematical ideas.

\section{The third subject}

The third subject used an almost similar way to the second subject to solve the mathematics problem given. He started answering the question by making mathematics symbols and identifying facts and data. The symbols were made from the initial name of the characters stated in the question. Budi was symbolized with 'B', Zahra was symbolized with ' $Z$ ', Nadia was symbolized with 'N', and Rani was symbolized with ' $R$ '. Then, he identified the facts and data from the question, such as

$B=14$ dozen $=14 \times 12=168$ books $;+N=B+R ; Z=\frac{3}{4} R ; N=R-5$ dozen; and $R=$ ?

However, it was found that, initially, the third subject also made mistake in making the symbols. It is proved by the correction made in his writing. See this figure 7.

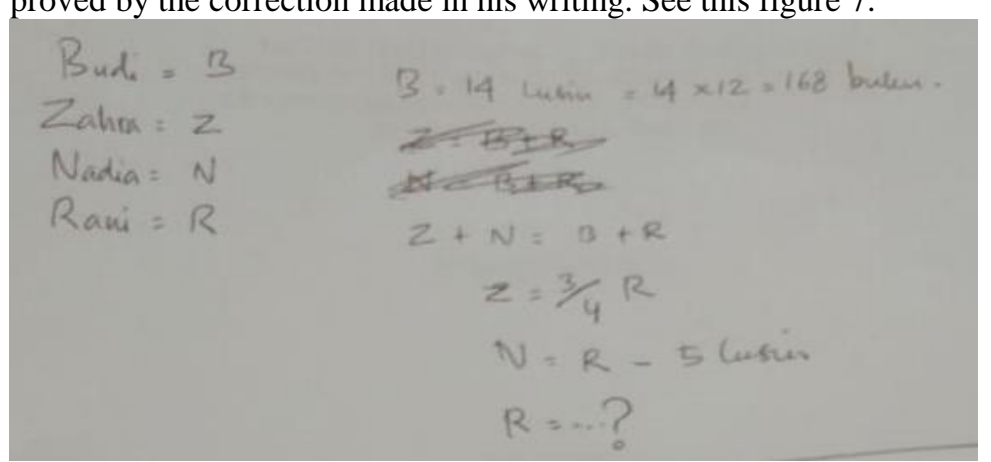

Figure 7

Mathematics Symbols and the Results of Facts Identification by the Third Subject

In the next step, he operated the symbols into mathematics operation to solve the problem. The result is presented in the following figure. 


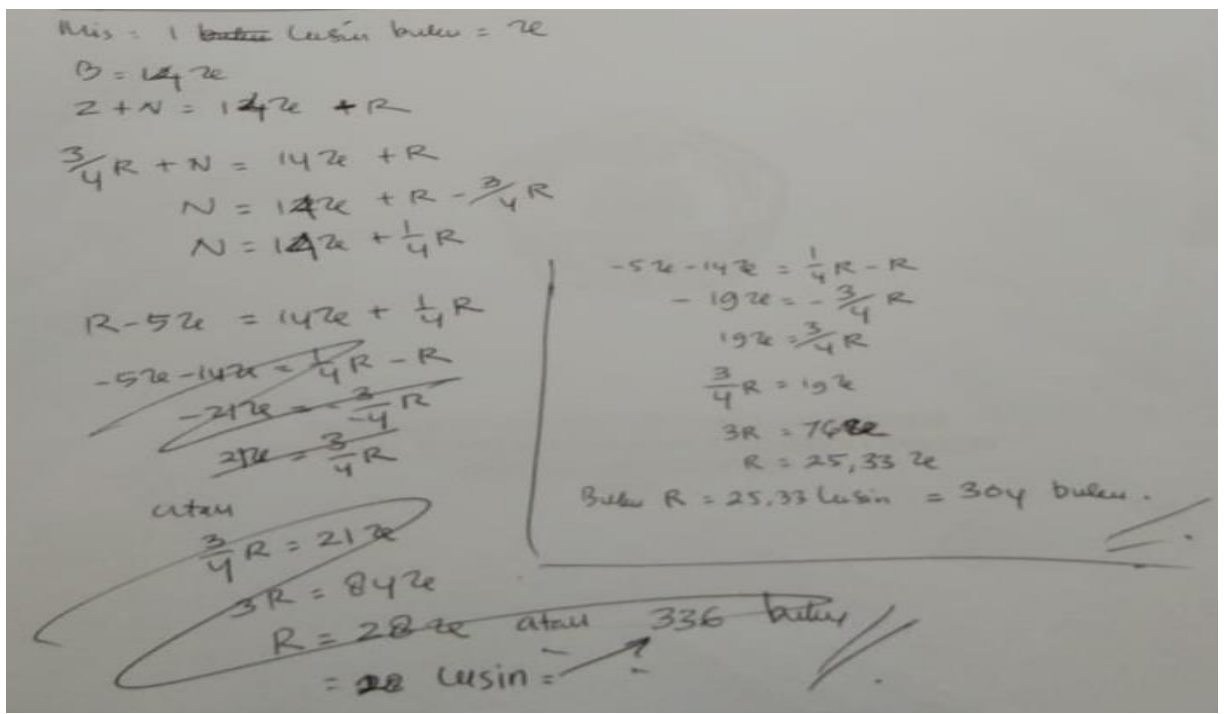

Figure 8

The Third Subject's Operation of Mathematical Symbols and Notations to Solve the Problem

From figure 8 above, it is seen that the third subject also made mistake in operating the symbols and notations. At first, his final answer was 336 books or 28 dozen. Then, he knew that it was wrong. After that, he scribbled on the wrong part and revised his answer next to the previous part. From this document analysis, it is inferred that the third subject also has the average skill of MCS in terms of written language indicated by his average ability to use of terms, notations, and symbols to present mathematical ideas.

After analyzing the documents, the researchers conducted an in-depth interview to get more comprehensive data dealing with the students' MCS. When the first subject was interviewed, he answered the question in a fluently spoken language. He also stated that he did not find any significant difficulty to solve the problem. Therefore, it is no wonder that he could write the mathematical symbols and notations fluently. The following is the interview excerpt.

“..... So far, I didn't find any difficulties to answer the question. I just need to comprehend the narrative question given carefully. Then, I started identifying some facts and data provided in the question. After that, I made mathematical symbols to make me easy to answer the question. After everything was fixed, I operated those symbols and started answering the question". (AFH/the first subject)

The next was the second subject. When he was interviewed, his answer was interrupted with hesitation. It seems that he got difficulties to express his ideas. When he was asked about the way he wrote mathematical symbols and notations, he replied that he wrote so because he was interfered by the name of the characters written in the question. So, he used the first letter of the characters' name, such as B for Budi, Z for Zahra, $\mathrm{N}$ for Nadia, and R for Rani. Further, he also admitted that he made mistake when he operated the symbols and notations into mathematical operations. Once he knew the mistake, then, he revised it. At last, he could find the correct answer to the question. The following is the interview excerpt.

“..... ummm... I wrote the symbols based on umm... the name of the characters. Umm... yeah, such as mmmm... B for Budi, Z for Zahra, N for Nadia, and R for Rani... Yes, it's the first letter of the name. I 
think it is easier for me. ....... yeah, I knew that I made mistake at first when I answered the question. Mmm.. after I rechecked my answer, I knew the mistake, and I revised it". (FRHN/the second subject)

The similar answer to the second subject's was also gotten from the third subject. In writing the symbols and notations, he used the first letter of the characters' name, such as B for Budi, Z for Zahra, $\mathrm{N}$ for Nadia, and $\mathrm{R}$ for Rani. He also stated that he felt confused with his mathematical operation when he answered the question so that his first answer was wrong. Then, he rechecked his answer and found that it was wrong. Soon, he revised his answer. The following is the interview excerpt.

“...... yes, I made the symbols based on the initial letter of the characters' name in the question. B for Budi, Z for Zahra, $N$ for Nadia, and R for Rani.... Yeah, when I answered the question, I felt confused with my mathematics symbols. I made mistake when I conducted the mathematical operation with those symbols. The mistake leads to the wrong answer I got. But, when I rechecked my answer for the second time, I identified the mistake. Then, I revised it again". (AM/the third subject)

From the data yielded from observation, documents analysis, and interview, it was confirmed that the first subject was the only subject who has good mathematical communication skills. He is able to express mathematical ideas; understand, interpret and assess or respond to mathematical ideas; and use terms, notations, and symbols to present mathematical ideas.

This study is in line with some scholars' research, such as: Rustam and Ramlan (2018), Freeman, Higgins, and Horney (2016), and Hirschfeld-Cotton (2008). Rustam and Ramlan (2018) conducted a study entitled 'Analysis of Mathematical Communication Skills of Junior High School Students of Coastal Kolaka'. This study revealed that the Mathematical Communication Skills of coastal students of Kolaka Regency is still low category. The first indicator is the ability to draw, including the ability to declare a situation or mathematical ideas in the form of tables or drawings. The second indicator is the ability to make mathematical expressions, including the ability to express situations, tables or images into language, symbols, ideas, or mathematical models. The third indicator is the ability to explain ideas, situations, and mathematical relations in writing and revisit a description or paragraph. Freeman, Higgins, and Horney (2016) conducted a study designed to examine the influence of multimodal writing on the communication of mathematical ideas. Elementary school students (ages 813) were required to write mathematics notes using two digital writing technologies, a personal digital notepad and a social mathematics blog, in the context of a formal intervention. Forty-two students participated, across three schools. The study showed that when students wrote notes that could be assessed for correctness, their answers was predominately right, indicating that mathematical sensemaking was taking place. Hirschfeld-Cotton (2008) investigated the use of mathematical communication, through oral homework presentations and written journals entries, and its impact on conceptual understanding of mathematics. The findings revealed that challenging students to communicate mathematics both orally and in writing deepened the students' understanding of the mathematics. Levels of understanding deepened when a variety of instructional methods were presented and discussed where students could comprehend the ideas that best suited their learning styles. Increased understanding occurred through probing questions causing students to reflect on their learning and re-evaluate their reasoning. Meanwhile, this study was focused on analyzing students' mathematical communication skills in solving a mathematics problem. The findings of this study show that 1 out of 3 students' is able to express mathematical ideas; understand, interpret and assess or respond to mathematical ideas; and use terms, notations, and symbols to present mathematical ideas.

NCTM (2000) and Greenes and Schulman (1996) elaborated that the indicators of mathematical communication skills are (1) understanding mathematical ideas that are presented in the writing or oral, (2) revealing the mathematical ideas in writing or oral, (3) using mathematics language approach (notation, term and symbol) to represent mathematical information, (4) using representations mathematics (the formula, diagram, tables, graphs, model) to represent mathematical information, and 
(5) changing and interpreting mathematical information in the representation of the mate of a different turn discoverable. Dealing with this study, the indicators of MCS used were understanding mathematical ideas that are presented in writing or oral, revealing the mathematical ideas in writing or oral, and using mathematics language approach (notation, term, and symbol) to represent mathematical information. Communication skills are essential in mathematics learning. Pourdavood \& Wachira (2015) asserted that through mathematical communication and discourse, teachers can foster student engagement and participation while focusing on the deep conceptual understanding called for in the Common Core mathematics standards. Further, they also stated that students who communicate their mathematical thinking and reasoning will become observers of themselves. They make invisible mathematical solutions clearer and more visible to themselves and to their peers. This study is beneficial since it gives a valuable insight to mathematics teachers, especially in Indonesia, that mathematical communication skills (MCS) are something pivotal in the mathematics education context. It could influence students' understanding and mastery in Maths lesson. From this study, it was proven that the students having good MCS also have a good understanding of Maths. The way the students converted mathematical problems into symbols and notations really affect the students' ability to solve the mathematics problems.

\section{CONCLUSION AND SUGGESTIONS}

The findings of this study reveal that only 1 out of 3 students' is able to express mathematical ideas; understand, interpret and assess or respond to mathematical ideas; and use terms, notations, and symbols to present mathematical ideas. There were three participants selected for this study since this study belongs to qualitative study. The sample size used in qualitative research methods is often smaller than that used in quantitative research methods. This is because qualitative research methods are often concerned with garnering an in-depth understanding of a phenomenon or are focused on meaning which are often centered on the how and why of a particular issue, process, situation, subculture, scene or set of social interactions. This study implies that the students' mathematical communication skills are still needed to be developed. This study should be taken into account by the Mathematics teachers to not only teach mathematics but also stimulate the students' mathematical communication skills through creative and innovative learning activities. Students' verbal and written communication helps their classroom teachers to understand students' understanding. Therefore, students' communication and classroom discourse not only enhance student learning but also informs the teacher's instructional decision making. Classroom communication and discourse are powerful tools for teachers to assess students' learning and can create a safe environment for risk-taking, exploring ideas, and genuine dialogue. Furthermore, it may involve parents regarding their children's education build a stronger communication between the classroom teacher and parents.

\section{REFERENCES}

Bishop, J. P. (2012). She's always been the smart one. I've always been the dumb one: Identities in the mathematics classroom. Journal for Research in Mathematics Education, 43(1), 34-74.

Creswell, J. W. (2012). Educational research: Planning, conducting and evaluating quantitative and qualitative research (4th ed.). Boston: Pearson Education Inc.

Dworkin, S. L. (2012). Sample size policy for qualitative studies using in-depth interviews. Arch Sex Behave, 41, 1319-1320. DOI: 10.1007/s10508-012-0016-6.

Ezrailson, C., Kamon, T., Loving, C. C., \& McIntyre, P. M. (2006). Teaching through interactive engagement: Communication is experience. School Science and Mathematics, 106(7), 278-279.

Freeman, B., Higgins, K. N., \& Horney, M. (2016). How students communicate mathematical ideas: An examination of multimodal writing using digital technologies. Contemporary Educational Technology, 7(4), 281-313 
Gay, A. S. (2008). Helping teachers connect vocabulary and conceptual understanding. Mathematics Teacher, 102(3), 218-223.

Greenes, \& Schulman. (1996). Communication processes in mathematical. exploration and investigation. USA: The National Council of Teachers of Mathematics, Inc.

Hirschfeld-Cotton, K. (2008). Mathematical communication, conceptual understanding, and students' attitudes toward mathematics. Action Research Projects. 4. Retrieved from http://digitalcommons.unl.edu/mathmidactionresearch/4.

Jansen, A. (2006). Seventh graders' motivations for participating in two discussion-oriented mathematics classrooms. Elementary School Journal, 106(5), 409-428.

Kabasakalian, R. (2007). Language and thought in mathematics staff development: A problem probing protocol. Teachers College Record,109(4), 1-21.

Manouchehri, A. (2007). Inquiry-discourse: Mathematics instruction. Math. Teac., 101(4), 290-300.

Manouchehri, A., \& St. John, D. (2006). From classroom discussions to group discourse. Mathematics Teacher, 99(8), 544-551.

Mullis, I. V. S., Martin, M. O., Foy, P., \& Arora, A. (2012). TIMSS 2011 international results in Mathematics. Chestnut Hill, MA, \& Amsterdam: TIMSS \& PIRLS International Study Center, Lynch School of Education, Boston College \& International Association for the Evaluation of Educational Achievement (IEA). Retrieved from https://timssandpirls.bc.edu/timss2011/downloads/T11_IR_Mathematics_FullBook.pdf .

National Council of Teachers of Mathematics. (2000). Principles and standards for school mathematics. Reston, VA: National Council of Teachers of Mathematics.

OECD. (2010). PISA 2009 results: Executive summary. Retrieved from https://www.oecd.org/pisa/pisaproducts/46619703.pdf.

Ontario Ministry of Education. (2005). Mathematics: The Ontario curriculum, grades 1-8 (Rev. Ed.). Toronto, Ontario: Queen's Printer for Ontario. Retrieved from http://www.edu.gov.on.ca/eng/curriculum/elementary/math18curr.pdf.

Patton, M. Q. (2002). Qualitative research and evaluation methods. Thousand Oaks, CA: Sage.

Pourdavood, R. G., \& Wachira, P. (2015). Importance of mathematical communication and discourse in secondary classrooms. Global J. of Sci. Frontier Res.: F Math. and Decision Sciences, 15(10).

Rustam, A., \& Ramlan, A. M. (2017). Analysis of mathematical communication skills of Junior High School students of coastal Kolaka. Journal of Mathematics Education, 2(2), 45-51.

Rohmah, I.I.T (2017). Classroom interaction in English language class for students of economics education. Arab World English Journal, 8(2), 192-207.

Small, M. (2013). Making math meaningful to Canadian students, K-8. Toronto: Nelson Education.

Schwols, A., \& Dempsey, K. (2012b). Making connections: Mathematical practices, assessment, and instruction. Presentation at the North Dakota Curriculum Initiative, Bismarck, ND.

Williams, M. M., \& Casa, T. M. (2012). Connecting class talk with individual student writing. The National Council of Teachers of Mathematics, 18(5), 314-321.

Yin, R. K. (2003). Case study research: Design and methods. Thousand Oaks, CA: Sage. 